\title{
Optical approach to analysis of interaction of gallium nitride and weak magnetic fields
}

\author{
R.A.Red'ko \\ V.Lashkaryov Institute of Semiconductor Physics, National Academy of \\ Sciences of Ukraine, 45 Nauki Ave., 03028 Kyiv, Ukraine
}

Received January 23, 2015

\begin{abstract}
The long-term transformations of optical transmittance of GaN epitaxial structure under weak magnetic field treatment $(B=60 \mathrm{mT}, f=10 \mathrm{~Hz}, \tau=1.2 \mathrm{~ms}, t=10 \mathrm{~min})$ were obtained. Optical measurements were performed in the waverange of $320-1100 \mathrm{~nm}$ at $300 \mathrm{~K}$. The method with three layers simulation was proposed for transmittance spectrum fitting. It was found that the treatment results in not only the optical film thickness changing, but probably in its refractive index too. Non-monotonous changes of the optical thickness, which formed interference, were obtained. Interpretation of the experimental results is based on diffusion of point defects after destruction of the metastable complexes from inner boundaries to surfaces of the studied structures.
\end{abstract}

Keywords: GaN, optical transmittance, weak magnetic field.

Получены долговременные трансформации оптических спектров пропускания эпитаксиальных $\mathrm{GaN}$ вследствие воздействия слабого магнитного поля ( $B=60$ мТл, $f=10$ Гц, $\tau=1.2$ мс, $t=10$ мин) в интервале $320-1100$ нм при $300 \mathrm{~K}$. Для моделирования полученных спектров предложена трехслойная модель исследуемой структуры. Выявлено, что в результате обработки меняется не только оптическая толщина пленки, которая формирует интерференционный сигнал, но и, вероятно, ее показатель преломления. Интерпретация полученных результатов основывается на диффузии продуктов распада (точечных дефектов) метастабильных комплексов, существующих на внутренней границе раздела фаз.

Оптичний підхід до аналізу взаємодії нітриду галію та слабкого магнітного поля. P.А.Редъко.

Отримано довготривалі трансформації оптичних спектрів пропускання епітаксійного $\mathrm{GaN}$ внаслідок впливу слабкого магнітного поля $(B=60$ мТл, $f=10$ Гц, $\tau=1.2$ мс, $t=$ 10 хв) в інтервалі 320-1100 нм при $300 \mathrm{~K}$. Для моделювання отриманих спектрів запропоновано тришарову модель дослідженої структури. Виявлено, що внаслідок обробки змінюється не тільки оптична товщина плівки, яка формує інтерференційний сигнал, але й, ймовірно, їі показник заломлення. Інтерпретація отриманих результатів грунтується на дифузії продуктів розпаду (точкових дефектів) метастабільних комплексів, існуючих на внутрішній границі розділу фаз.

\section{Introduction}

Gallium nitride $(\mathrm{GaN})$ is one of the most investigated semiconductors for device structure and it is one of the promising wide band-gap $(3.4 \mathrm{eV}$ at $300 \mathrm{~K})$ materials due to fabrication cost, efficient photoemission properties in optical wavelength range and the variety of techniques available for its deposition as a thin film. There are good number of reports [1-4] about growth and characterization of GaN thin films on different substrates. The GaN thin films have been extensively deeply studied for its structural, optical and optoelectronic properties [4]. 
Despite the fact that gallium nitride has been investigated extensively, there are however many issues that still need to be understood to optimize its optical and electrical properties. For such optimization different technological methods as well as weak magnetic fields (WMF) can be applied. In this paper we propose the model for simulating three-layer oxide $/ \mathrm{GaN} / \mathrm{Al}_{2} \mathrm{O}_{3}$ structure for more reliability analyze of processes which occur in multi-layer materials after noted treatments.

\section{Experimental}

GaN thin films were prepared on $\mathrm{Al}_{2} \mathrm{O}_{3}$ substrate using the metal-organic chemical vapor deposition (MOCVD) technique. Thicknesses of top (gallium nitride) and bottom $\left(\mathrm{Al}_{2} \mathrm{O}_{3}\right)$ layers were 2.0-2.5 and $230 \mu \mathrm{m}$, respectively. The epitaxial layer was $n$-type, doped with Si. Concentration of carriers was $\sim 1.6 \cdot 10^{19} \mathrm{~cm}^{-3}$. Spectral dependences of the optical transmittance (OT) of the studied structures were measured at $300 \mathrm{~K}$ with spectrophotometer Specord 210 in the 350-1100 $\mathrm{nm}$ wavelength range, with an error below $0.1 \mathrm{~nm}$. Since the WMF treatment $(B=60 \mathrm{mT}, f=10 \mathrm{~Hz}, \tau=1.2 \mathrm{~ms})$ was the most efficient for III-V semiconductor materials [5], it was chosen for our experiments with duration of processing $10 \mathrm{~min}$.

\section{Results and discussion}

Fig. 1 shows initial transmittance spectrum of the material under investigation in the wavelength range of $350-1100 \mathrm{~nm}$. One can see two characteristic regions: a typical straight-line in the blue range and oscillation at wavelengths of $400-1100 \mathrm{~nm}$. The value of $3.40 \mathrm{eV}$ (bandgap of GaN) was obtained by extrapolation of the first one. Oscillations in OT spectrum are related to the internal structure of the material, namely, the presence of a clear semiconductor-insulator interface. But it could be cases, when interference in red region was not appears. The transmittance curve $T_{\alpha}=\left(T_{\max } T_{\min }\right)^{1 / 2}$ [6] in this case observed (Fig. 1). It responds to feeble technique sensibility and/or not-requiring to interference condition observing. Moreover, it is real transmittance spectrum for the film under investigation (GaN in our case), and exactly this curve we will analyze in future.

Some simulation is needed to obtain $T_{\alpha}$ curve in theoretical way. The structure under investigation $\left(\mathrm{GaN} / \mathrm{Al}_{2} \mathrm{O}_{3}\right)$ can be in

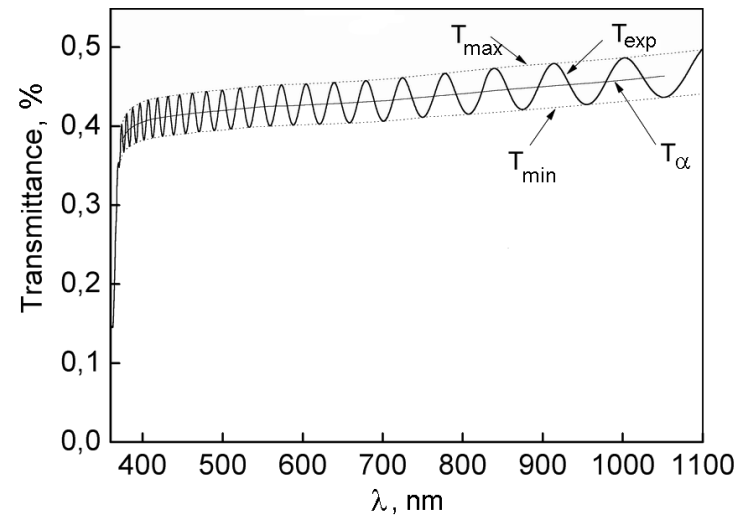

Fig. 1. Initial OT spectrum of $\mathrm{GaN} / \mathrm{Al}_{2} \mathrm{O}_{3}$.

three-layers model approximated (Fig. 2). We have chosen a model with thin oxide layer, which always exists at the semiconductor surface. In this work interference effects we will not take into account, so the changing of the phase at interface of the layers with different refractive indexes for reflected/transmitted wave we will not take into account.

Let the thickness of the modeled layers are $d_{1}, d_{2}, d_{3}$ for the oxide layer, GaN-epitaxial film and $\mathrm{Al}_{2} \mathrm{O}_{3}$-substrate, respectively; refractive indexes are $n_{0}, n_{1}, n_{2}, n_{3}$ for air, oxide layer, GaN-epitaxial film and $\mathrm{Al}_{2} \mathrm{O}_{3}$-substrate, respectively; $r_{0}, r_{1}, r_{2}, r_{3}$ - reflection coefficients for interfaces airoxide layer, oxide layer-GaN film, GaN film-substrate, substrate-air, respectively; $I_{0}$ - initial intensity of the electromagnetic wave, $I_{1}$ - intensity of the wave passed oxide layer, $I_{2}$ - intensity of the wave passed GaN-film, $I_{3}$ - intensity of the wave passed $\mathrm{Al}_{2} \mathrm{O}_{3}$-substrate, $I$ - intensity of the wave passed entire structure (see Fig. 2).

Assuming the reflection at the interface between the layers and according to the Buggery-Lambert law, we can write:

$$
\begin{gathered}
I_{1}=\left(I_{0}-r_{0} I_{0}\right) e^{-\alpha_{1} d_{1},} \\
I_{2}=\left(I_{1}-r_{1} I_{1}\right) e^{-\alpha_{2} d_{2},}, \\
I_{3}=\left(I_{2}-r_{2} I_{2}\right) e^{-\alpha_{3} d_{3}}, \\
I=\left(I_{3}-r_{3} I_{3}\right) .
\end{gathered}
$$

Solving expressions (1)-(4) we would have:

$$
\begin{gathered}
I= \\
=I_{0}\left(1-r_{0}\right)\left(1-r_{1}\right)\left(1-r_{2}\right)\left(1-r_{3}\right) e^{-\left(\alpha_{1} d_{1}+\alpha_{2} d_{2}+\alpha_{3} d_{3}\right)} .
\end{gathered}
$$




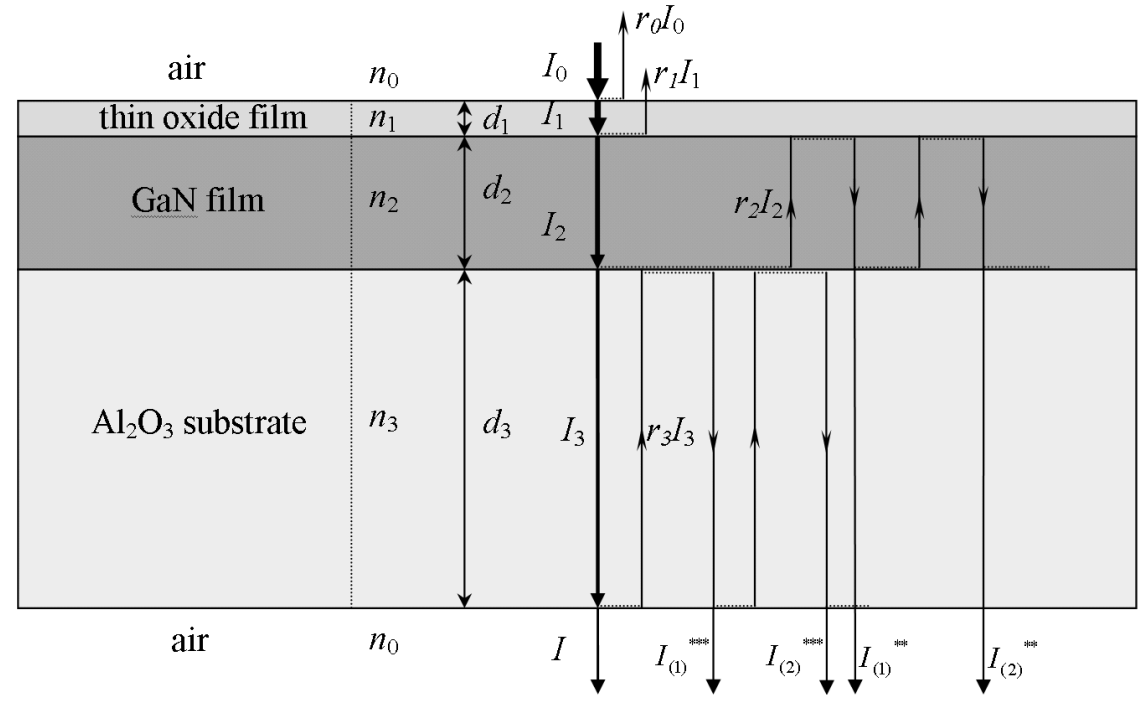

Fig. 2. Model of $\mathrm{GaN} / \mathrm{Al}_{2} \mathrm{O}_{3}$ structure under investigation (explanation of symbols see in the text).

But, the absorption in thin oxide layer, obviously, is too small to be accounted, so the expression (5) should be change to:

$$
I=
$$

$=I_{0}\left(1-r_{0}\right)\left(1-r_{1}\right)\left(1-r_{2}\right)\left(1-r_{3}\right) e^{-\left(\alpha_{2} d_{2}+\alpha_{3} d_{3}\right)}$.

Neglecting the extinction coefficient for $\mathrm{GaN}$ in the investigated spectral region, the reflection coefficients for interfaces can be writing as follows:

$$
\begin{aligned}
& r_{0}=\left(\frac{n_{1}-n_{0}}{n_{1}+n_{0}}\right)^{2} . \\
& r_{1}=\left(\frac{n_{2}-n_{1}}{n_{2}+n_{1}}\right)^{2} . \\
& r_{2}=\left(\frac{n_{3}-n_{2}}{n_{3}+n_{2}}\right)^{2} . \\
& r_{3}=\left(\frac{n_{0}-n_{3}}{n_{0}+n_{3}}\right)^{2} .
\end{aligned}
$$

It should be noted, that after reflections at the inner boundaries, waves with intensities $r_{1} I_{1}, r_{2} I_{2}$ and $r_{3} I_{3}$ (see Fig. 2) take part in multiple reflections. And after first internal reflection, it will contribute in total transmitted intensity their own parts: $I^{\bullet}$, $I^{\bullet \bullet}$ and $I^{\bullet \bullet \bullet}$, respectively.

The behavior of $r_{1} I_{1}$-wave we will not consider because of neglecting part of this term. After first reflection of $r_{2} I_{2}$-wave at the interface of GaN-oxide and passing through $\mathrm{Al}_{2} \mathrm{O}_{3}$ layer, it will have the intensity:

$$
I_{(1)}^{\bullet \bullet}=
$$

$$
=I_{0}\left(1-r_{0}\right)\left(1-r_{1}\right)\left(1-r_{2}\right)\left(1-r_{3}\right) e^{-3 \alpha_{2} d_{2}-\alpha_{3} d_{3}} r_{2} r_{2}^{\prime} \text {, }
$$

where

$$
r_{2}^{\prime}=\left(\frac{n_{1}-n_{2}}{n_{1}+n_{2}}\right)^{2}
$$

is the reflection coefficient for the direction GaN-oxide.

After second reflection of $r_{2} I_{2}$-wave at the interface of $\mathrm{GaN}$-oxide and passing through $\mathrm{Al}_{2} \mathrm{O}_{3}$ layer, it will have the intensity

$$
\begin{array}{cc}
I_{(2)}^{\bullet \bullet}= & (13) \\
=I_{0}\left(1-r_{0}\right)\left(1-r_{1}\right)\left(1-r_{2}\right)\left(1-r_{3}\right) e^{-5 \alpha_{2} d_{2}-\alpha_{3} d_{3}} & r_{2}^{2} r_{2}^{\prime 2} .
\end{array}
$$

Every next reflection will give a some contribution $I_{(\mathrm{i})}{ }^{\bullet \bullet}$. It is easy to see that we will have a declining geometric progression. The sum of the last is:

$$
\begin{gathered}
I^{\bullet \bullet}=\sum I_{(i)}^{\bullet \bullet}= \\
=\frac{I_{0}\left(1-r_{0}\right)\left(1-r_{1}\right)\left(1-r_{2}\right)\left(1-r_{3}\right) e^{-3 \alpha_{2} d_{2}-\alpha_{3} d_{3}} r_{2} r_{2}^{\prime}}{1-r_{2} r_{2}^{\prime} e^{-2 \alpha_{2} d_{2}}} .
\end{gathered}
$$

If we will think analogous about $r_{3} I_{3}{ }^{-}$ wave we should have:

$$
\begin{gathered}
I^{\bullet \bullet \bullet}=\sum I_{(i)}^{\bullet \bullet \bullet}= \\
=\frac{I_{0}\left(1-r_{0}\right)\left(1-r_{1}\right)\left(1-r_{2}\right)\left(1-r_{3}\right) e^{-\alpha_{2} d_{2}-3 \alpha_{3} d_{3}} r_{3} r^{\prime}}{1-r_{3} r^{\prime}{ }^{\prime} e^{-2 \alpha_{3} d_{3}}}
\end{gathered}
$$

Functional materials, 22, 2, 2015 
where

$$
r_{3}^{\prime}=\left(\frac{n_{2}-n_{3}}{n_{2}+n_{3}}\right)^{2}
$$

is the reflection coefficient for the direction substrate-GaN. Thus, total transmitted intensity will be sum of expressions (6), (14) and (15):

$$
I_{t o t}=I+I^{\bullet \bullet}+I^{\bullet \bullet \bullet} .
$$

So, measured transmittance should be $T=I_{\text {tot }} / I_{0}$ :

$$
\begin{aligned}
& T=\left(1-r_{0}\right)\left(1-r_{1}\right)\left(1-r_{2}\right)\left(1-r_{3}\right) e^{-\left(\alpha_{2} d_{2}+\alpha_{3} d_{3}\right) \times} \\
& \times\left[1+\frac{r_{2} r_{2}^{\prime} e^{-2 \alpha_{2} d_{2}}}{1-r_{2} r^{\prime}{ }_{2} e^{-2 \alpha_{2} d_{2}}}+\frac{r_{3} r^{\prime}{ }_{3} e^{-2 \alpha_{3} d_{3}}}{1-r_{3} r^{\prime}{ }_{3} e^{-2 \alpha_{3} d_{3}}}\right] .
\end{aligned}
$$

It is clear that we have considered not all of possible wave reflections inside the structure, but all of them have a magnitude with higher order of smallness. For objective estimation of the reliability of the noted approximation one can propose a parameter:

$$
\beta=\left(r_{2} r_{2}^{\prime}\right)\left(r_{3} r_{3}^{\prime}\right) e^{-2\left(\alpha_{2} d_{2}+\alpha_{3} d_{3}\right)}
$$

If $\beta \leq 1$, all the above considerations are true. Physically, this means that the reflection from the interfaces of oxide-film and film-substrate should not be too large and/or analyzed layers should not have very small optical thicknesses.

Refractive index for GaN was obtained with method, described in [6]. The fitting was provided with next Sellmeir dispersion relationships for $\mathrm{GaN}$ and $\mathrm{Al}_{2} \mathrm{O}_{3}$, respectively [7]:

$$
n_{2}=\sqrt{1+\frac{4.391 \lambda^{2}}{\lambda^{2}-123.309^{2}}},
$$

$n_{3}=\sqrt{1+\frac{1.431 \lambda^{2}}{\lambda^{2}-0.073^{2}}+\frac{0.651 \lambda^{2}}{\lambda^{2}-0.119^{2}}+\frac{5.341 \lambda^{2}}{\lambda^{2}-18.028^{2}}(21)}$

Apparently, the oxide film mostly should have gallium oxide and nitrogen oxide phases. Optical parameter $\mathrm{n}$ for oxide film was obtained as some averaging of refractive indexes for $\mathrm{Ga}_{2} \mathrm{O}_{3}$ [8] and $\mathrm{NO}$ [9] and was constant 1.615 . The resulting dependence for the optical transmittance (18) is a function of wavelength, since refractive indices depend on $\lambda$, and can be used to determine both parameters $d$ and $n$ of the film in empirically way. It should be noted that

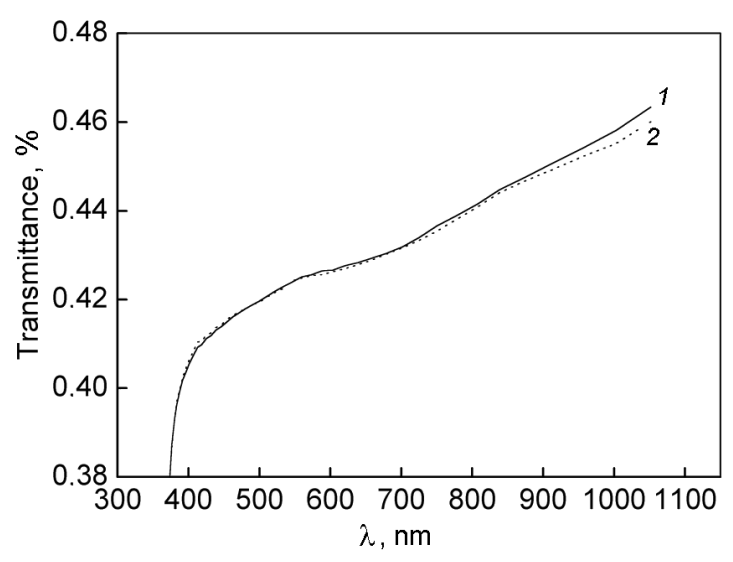

Fig. 3. Experimental and fitted curves of $T_{\alpha}$ for initial state of $\mathrm{GaN} / \mathrm{Al}_{2} \mathrm{O}_{3}$.

this method is most suitable to the case when the interference not appears in the transmission spectrum for whatever reason. The experimental and fitted with (18) curves for the initial state are shown in Fig. 3.

One can see that theoretical fitting and experiment are in a good agreement. Thus, noted approach is suitable for this model. And any changes in refractive indexes, optical thickness will transform the transmittance spectrum. So, this spectroscopic method is suitable for investigation of the interaction of semiconductor material (e.g. gallium nitride) with any alternative action - microwave radiation treatment, weak magnetic field and so on.

Let's try to apply this approach to the transformation of OT spectra, which observed after WMF treatment. In Fig. 4 simulated and experimental curves for $\mathrm{GaN} / \mathrm{Al}_{2} \mathrm{O}_{3}$, obtained during 15 days after treatment, are shown. The fitting was provided by meaning that the refractive index was not changed but any changes in optical transmittance spectra were related with optical thickness varying. The using expression (18) for simulation it was shown that varying of optical thickness ( $d_{2}$ in Eq.(18)) is not enough to explain the observed changing in OT spectra (parameters of $d_{2}$ are collected in Table). The fitted and experiment curves are not in agreement for red region of observed spectra. And this disagreement increases with the time after treatment.

The concept developed in [10], together with the results obtained in [5, 11] testify about not trivial mechanism of the interaction of WMF and semiconductor material. As can be seen from the presented results, 


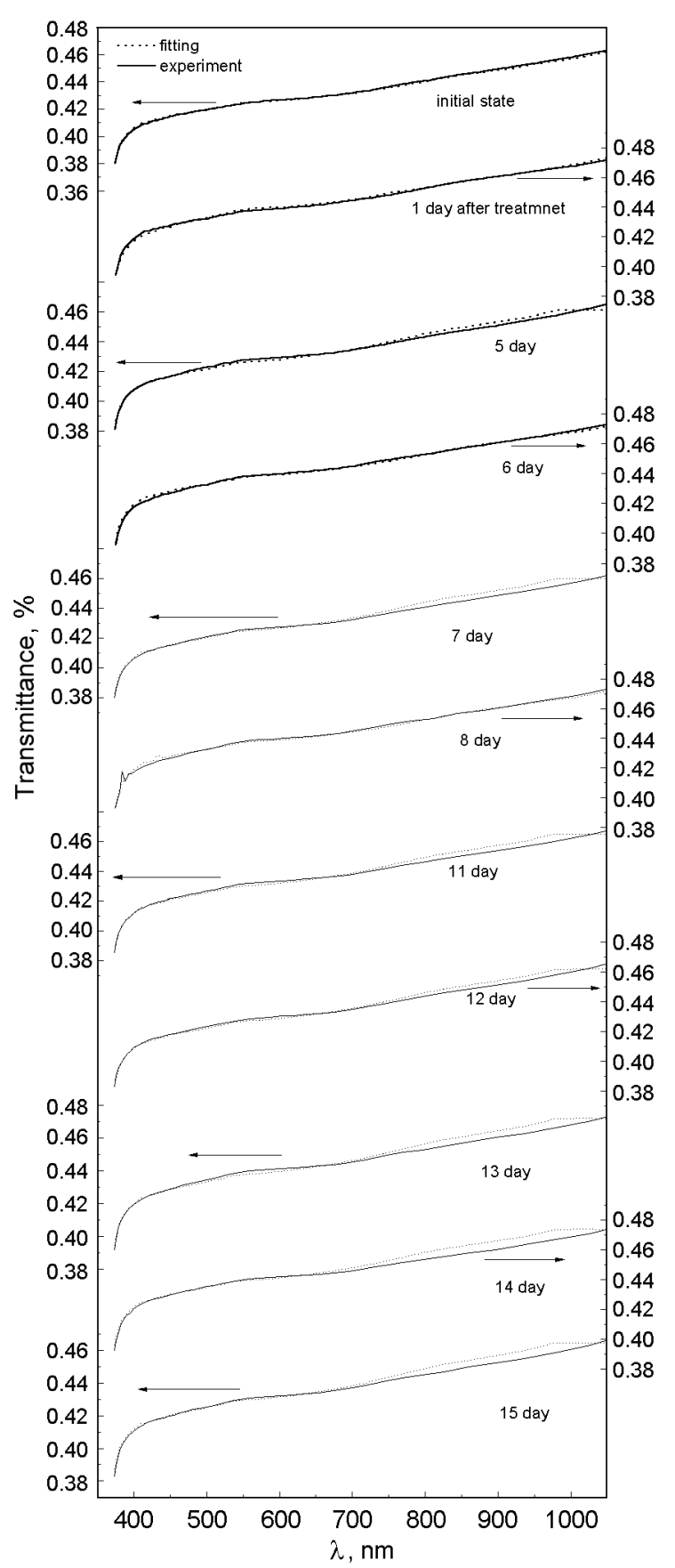

Fig. 4. Evolution of simulated and experimental curves due to WMF treatment.

simple variation of the film optical thickness occurred due to destruction of metastable defect complexes existed in the interface of film-substrate, is not able to explain the transformation of the optical transmission curves. There are only blue-regions of the simulated OT-curves in agreement with the experimental ones. While the red-regions of experimental and fitted curves are different. This could be the reason of the changing not only optical thickness of the interfering layer, but also its refractive index. Displacement of the experimental and simulated curves is not large - only about $1 \%$, but the sensitivity of this method suggests that it is above than the expected error. Regardless of the possible physical mechanisms of the observed transformations, one can argue that the chosen model allows to conclude that due to WMFtreatment the small, but nevertheless detected value, long-term changes in the refractive index of the studied material occur.

\section{Conclusions}

In summary, the dependences of OT spectra on the time after the WMF treatment of MOCVD-grown GaN epitaxial structures have been investigated. The results and conclusions of this study can be summarized as follows. The effect after the treatment is qualitatively the same for III-V compounds studied early [5, 11]. It consists in oscillatory changes of the optical thickness, which formed interference. It was found that the simulated and experimental curves demonstrate the disagreement in studied red spectral region after the treatment that, perhaps, testifies about more complicate processes, included refractive indexes of GaN changing due to WMF treatment. To establish micromechanisms of the observable reorganization, additional researches are required.

\section{References}

1. K.Forghani, L.Schade, U.T.Schwarz et al., J. Appl. Phys., 112, 093102 (2012).

2. M.Junaid, D.Lundin, J.Palisaitis et al., $J$. Appl. Phys., 110, 123519 (2011).

3. G.Yu, G.Wang, H.Ishikawa et al., Appl.Phys. Lett., 70, 3209 (1997).

4. M.A.Reshchikov, H.Morkoc, J. Appl. Phys., 97, 061301 (2005).

5. R.Red'ko, Appl.Surf. Sci., 258, 4073 (2012).

6. R.Swanepoel, J.Phys.E: Sci. Instrum., 16, 1214 (1983).

7. http://refractiveindex.info

8. R.C.West, Handbook of Chemistry and Physics, 1989-900 CRC, Boca Raton, Florida (1989).

9. D.Fulvio, B.Sivaraman, G.A.Baratta et al., Spectrochim., Acta Part A: Mol. and Biomol. Spectr., 72(5), 1007 (2009).

10. Yu.I.Golovin, Phys.Solid State, 46, 789 (2004).

11. R.Red'ko, J.Appl.Phys., 112, 073513 (2012). 